\title{
Measurement and Prediction of the Thermal and Electrical Conductivity of Al-Zr Overhead Line Conductors at Elevated Temperatures
}

\author{
Osman Kahveci ${ }^{a}$,Emin Çadirli ${ }^{b} *$, Mehmet Art ${ }^{a}$, Hicran Tecer ${ }^{c}$, Mehmet Gündüz ${ }^{a}$ \\ ${ }^{a}$ Department of Physics, Erciyes University, Faculty of Science, Kayseri, Turkey \\ ${ }^{b}$ Department of Physics, Faculty of Arts and Sciences, Niğde Ömer Halisdemir University, Niğde, \\ Turkey \\ ${ }^{c}$ Coreal Aluminyum Kablo A.Ş., Free Zone of Kayseri, Kayseri, Turkey
}

Received: July 23, 2018; Revised: October 05, 2018; Accepted: October 25, 2018

In the present work, the thermal conductivity and electrical resistivity of the Al-0.25 $\mathrm{Zr}$ (wt.\%) alloy have been investigated from $300 \mathrm{~K}$ to $600 \mathrm{~K}$. The variations of thermal conductivity $\left(\mathrm{K}_{\text {total }}\right)$ with temperature were measured by using a radial heat flow furnace. The electrical resistivity $(\rho)$ measurements of the alloy depending on the temperature were performed using the standard four-point probe method. The electrical conductivity $(\sigma)$ was obtained by using the measured electrical resistivity. The thermal conductivity and the electrical resistivity coefficients were determined from the graphs of thermal and electrical resistivity versus temperature for the alloy. The electronic thermal conductivity $\left(\mathrm{K}_{\mathrm{e}}\right)$ values were obtained from the Wiedemann-Franz and Smith-Palmer equations, and the values of $\mathrm{K}_{\mathrm{L}}$ were obtained by subtracting $\mathrm{K}_{\mathrm{e}}$ fromthe measured values $\left(\mathrm{K}_{\text {total }}\right)$. $\mathrm{K}_{\text {total }}$ is dominated by $\mathrm{Ke}$, and $\mathrm{K}_{\mathrm{e}}$ varies between 208-198 W/mK. The $\mathrm{K}_{\mathrm{L}}$ decreases from 7.99 to $1.77 \mathrm{~W} / \mathrm{m} \mathrm{K}$, and $\sigma$ varies between $1.41 \times 10^{7}-2.80 \times 10^{7} \Omega^{-1} \mathrm{~m}^{-1}$ in the range of temperature $373-600 \mathrm{~K}$. The enthalpy of fusion $(\Delta \mathrm{H})$ and the specific heat capacity $\left(\mathrm{C}_{\mathrm{p}}\right)$ during the transformation were determined. Thermal diffusivity $(\alpha)$ changes were calculated as a function of temperature from these obtained thermal data.

Keywords: Electrical resistivity, Electrical conductivity, Total thermal conductivity, Lattice thermal conductivity, Electronic thermal conductivity, Al-Zr Alloy.

\section{Introduction}

Aluminum is the second most used metal due to its desirable thermal and electrical properties. Furthermore, it is a crucial component of an important category of technological materials. Due to its high strength to weight ratio, aluminum and its alloys are used in a wide range of industrial applications such as transportation, particularly with aircraft and space vehicles, construction and building, containers, packaging and electrical transmission lines ${ }^{1}$. Aluminum and its alloys are also used in all bare overhead energy transmission lines. Researchers and manufacturers have made significant improvements in the tensile strength and conductivity of the overhead lines. They have also been developing design and productions that will increase service life and operating temperatures ${ }^{2-9}$. Zirconium additions $(0.1$ to $0.3 \%$ ) to $\mathrm{Al}$ have been reduced the as-cast grain size and increased the operating temperatures of Al-Zr alloys up to $210{ }^{\circ} \mathrm{C}$ without a loss in the tensile strength ${ }^{7}$.

It is very important to know the thermal and electrical conductivities of the materials used in transmission lines. In the experimental determination of the thermal conductivity (K) of solids, a number of different methods of measurement are required for different ranges of temperature and for various classes of materials having different ranges of $\mathrm{K}$ values. One of the common techniques for measuring the thermal conductivity of solids is the radial heat flow method. The radial heat flow method is a steady state method ${ }^{10}$. The temperatures within the sample are measured by thermocouples. This method has been widely used for measuring the thermal conductivity of solids for pure materials and alloys ${ }^{11-13}$. Thermal transport in metals is complex due to the coexistence of electron and phonon conduction and the strong interaction between them. The total thermal conductivity $\left(\mathrm{K}_{\text {tot }}\right)$ has two components: The electronic thermal conductivity $\left(\mathrm{K}_{\mathrm{e}}\right)$ and the lattice (or phonon) thermal conductivity $\left(\mathrm{K}_{\mathrm{L}}\right)$. The total thermal conductivity is the sum of these two components.

$$
K_{\text {tot }}=K_{e}+K_{L}
$$

The contribution of electrons is greater than that of phonon at all temperatures in pure metals. The relative importance of $\mathrm{K}_{\mathrm{e}}$ and $\mathrm{K}_{\mathrm{L}}$ thus depends on the magnitude of $\mathrm{K}_{\mathrm{L}}$. The electronic component often paralells the electrical conductivity, and the electrical conductivity is the highest in pure metals but reduced in the case of alloys and even lower in semimetals and semiconductors ${ }^{14}$. In particular, by assuming the lattice thermal conductivity $\left(\mathrm{K}_{\mathrm{L}}\right)$ is negligible in a metal, $\mathrm{K}_{e}$ could be linked with the electrical conductivity $(\sigma)$ by using the well-established Wiedemann-Franz (W-F) law ${ }^{14}$ :

$$
K_{e}=\sigma L T
$$


where $\mathrm{L}$ is Lorenz number $\left(=2.44 \times 10^{-8} \mathrm{~W} \Omega / \mathrm{K}^{2}\right)$ and $\mathrm{T}$ is the absolute temperature. Based on the W-F law, SmithPalmer (S-P) suggested the following equation ${ }^{15,16}$

$$
K_{e}=A \sigma L T+B
$$

where $\mathrm{A}$ is the Lorenz number difference among different alloys, and $\mathrm{B}$ stands for the constant lattice thermal conductivity. Smith and Palmer ${ }^{15,16}$ determined $A=0.909$ and $B=10.5 \mathrm{~W} / \mathrm{Km} \mathrm{K}$ for Al-based alloys. The relationship between the $\mathrm{K}$ and $\sigma$ of alloys, specifically aluminum alloys (without silicon), is established by using the W-F equation ${ }^{14}$ and the S-P equation ${ }^{15,16}$. The investigations of the $\mathrm{K}$ and $\sigma$ of aluminum rich Al-Zr alloy are crucial for many industrial applications. The thermal and electrical data may be used to see better insight into the thermo-electrical properties of Al-Zr alloy.

As seen in the Al-rich Al-Zr dilute phase diagram (Fig. 1), the terminal solid solution has a decreasing solid solubility as the temperature decreases ${ }^{17}$. Figure 1 shows this type of decrease of solid solubility in the thermal solid solution $\alpha-\mathrm{Al}$ from point a to point $\mathrm{b}$ along the solvus. There is a large decrease in solid solubility of solid solution in $\alpha$-Al in parallel with the decreasing temperature from $T_{a}$ to $T_{b}$.

Although the $\mathrm{K}$ and $\sigma$ of pure $\mathrm{Al}$ and pure $\mathrm{Zr}$ metals have been obtained theoretically and experimentally, only limited research has been performed on the effect of temperature on $\mathrm{K}$ and $\sigma$ of the Al-Zr alloys. $\mathrm{K}$ and $\sigma$ of the Al-Zr alloy with a wide range of temperatures have not been investigated. Therefore, in order to better understand the mechanism of

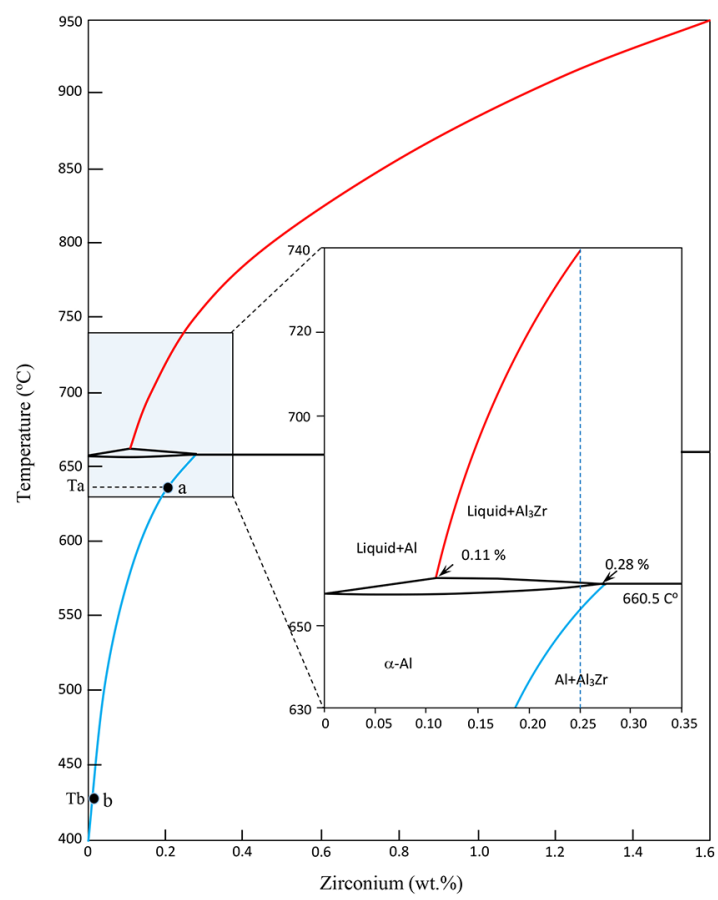

Figure 1. Al-rich corner of the Al-Zr phase diagram (adopted from ref. ${ }^{17}$ ) alloying elements on $\mathrm{K}$ and $\sigma$, it is necessary to study the $\mathrm{K}$ and $\sigma$ of the Al-Zr alloys.

The purpose of the present work was to determine the thermal conductivities $\left(\mathrm{K}_{\text {tot }}, \mathrm{K}_{\mathrm{e}}, \mathrm{K}_{\mathrm{L}}\right)$ and electrical conductivity $(\sigma)$ as a function of temperature for the Al-0.25 Zr alloy (all compositions are in wt.\% unless otherwise noted). Effects of temperature on $\mathrm{K}$ and $\sigma$ of Al-Zr alloy were investigated and correlated with the corresponding $\mathrm{K}$ and $\sigma$ on the basis of the W-F and S-P equations. This was done in three steps. In the first step, the variations of thermal conductivity of solid phases with temperature for the Al- $0.25 \mathrm{Zr}$ alloy were measured with a radial heat flow furnace. In the second step, a four-point probe measurement method is performed to determine the resistivity of the alloy sample depending on the temperature and the electrical conductivity, for which $\sigma$ was obtained by using the measured resistivity values. In the third step, the variations of $\mathrm{K}_{\mathrm{e}}$ and $\mathrm{K}_{\mathrm{L}}$ with temperature for the same alloy were determined from the W-F and S-P equations by using the measured values of $\sigma$. The values for $\mathrm{K}_{\mathrm{L}}$ were obtained by subtracting the values of $\mathrm{K}_{\mathrm{e}}$ from the measured values $\left(\mathrm{K}_{\text {tot }}\right)$ for studied Al-0.25 Zr alloy. Also, the thermal conductivity and electrical resistivity coefficients were determined from the related graphs.

\section{Experimental Procedure}

\subsection{Sample preparation and Identification of solid phases}

The Al-0.25Zr (wt.\% ) samples were produced using the Al-10 Zr master alloy and $99.8 \%$ pure Al. Three samples were prepared from the studied alloy for reproducibility during sample preparation. After allowing time for melt homogenization in a vacuum melting furnace, the molten alloy was poured into the prepared graphite crucibles (140 $\mathrm{mm}$ in length, $30 \mathrm{~mm}$ ID and $40 \mathrm{~mm}$ OD) that were held in a specially constructed hot-filling furnace at approximately 75-100 ${ }^{\circ} \mathrm{C}$ above the melting point of the alloy. The sample was stirred with a thin alumina rod. The samples were then directionally solidified from bottom to top using a water cooled $\mathrm{Cu}$ block to ensure that the crucibles were completely full.

The verified compositions given in Table 1 were obtained from the studied alloy system through bulk chemical analysis performed with direct current plasma emission spectroscopy (DPES). As seen in Table 1, the composition quantities of Al, $\mathrm{Zr}$ and other impurities were found to be $99.260 \%, 0.256 \%$ and $0.484 \%$, respectively. The EDX analysis was conducted at $20 \mathrm{keV}$ using the X-ray lines. According to the EDX results, as shown in Fig. $2 \mathrm{a}$, the gray phase is the Al-rich $\alpha-\mathrm{Al}$ matrix phase (Al-0.28 Zr), and the dark gray phase (white arrow) is $\mathrm{Al}_{3} \mathrm{Zr}$ intermetallic phase (Al-54.28 Zr). As seen in Fig. 2a, the composition of the produced alloy (nominal composition) was also found to be Al-0.28 Zr. The values obtained for $\alpha$-Al matrix phase are in agreement with the 
Table 1. The chemical composition analysis with direct current plasma emission spectroscopy (DPES) of the studied alloy (Al- $0.25 \mathrm{wt} . \% \mathrm{Zr}$ )

\begin{tabular}{cccccccccc}
\hline $\mathrm{Zr}$ & $\mathrm{Si}$ & $\mathrm{Fe}$ & $\mathrm{Cu}$ & $\mathrm{V}$ & $\mathrm{Ni}$ & $\mathrm{Zn}$ & $\mathrm{Ti}$ & Others & $\mathrm{Al}(\mathrm{Bal})$. \\
\hline 0.256 & 0.065 & 0.169 & 0.015 & 0.019 & 0.0014 & 0.077 & 0.016 & $<0.05$ & 99.260 \\
\hline
\end{tabular}
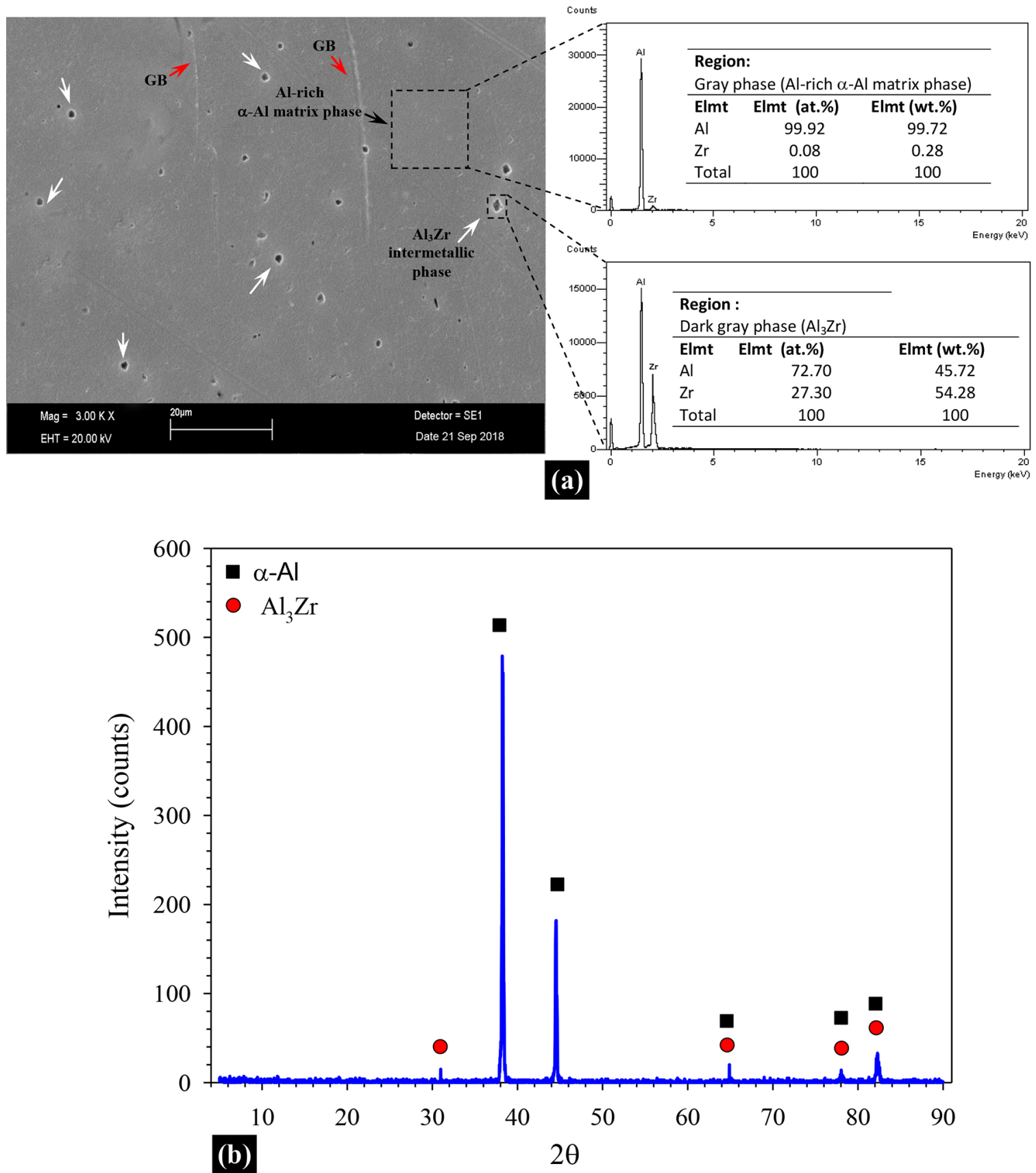

Figure 2. (a) The chemical composition analysis of the Al-0.25 $\mathrm{Zr}$ alloy obtained using SEM-EDX: white arrow ( $\mathrm{Al}_{3} \mathrm{Zr}$ intermetallic phase), black arrow (Al-rich $\alpha$-Al phase), and red arrow (GB: Grain boundary); (b) X-ray diffraction (XRD) patterns obtained from the Al- $0.25 \mathrm{Zr}$ alloy

nominal compositions of the samples. XRD data for phase identification of Al-0.25 Zr alloy are shown in Fig. 2b. In cast condition, the alloy exhibited peaks for $\alpha-\mathrm{Al}$ and $\mathrm{Al}_{3} \mathrm{Zr}$ phases. The peaks (black squares) at $37^{\circ}$ and $44^{\circ}$ strongly correspond to $\alpha$-Al phase, and the peaks (red circles) at $31^{\circ}$, $64^{\circ}, 78^{\circ}$ and $82^{\circ}$ correspond to $\mathrm{Al}_{3} \mathrm{Zr}$ intermetallic phase. Both EDX analysis (Fig. 2a) and XRD pattern (Fig. 2b) strongly indicate that only two phases $\left(\alpha-\mathrm{Al}\right.$ and $\left.\mathrm{Al}_{3} \mathrm{Zr}\right)$ are present in the microstructure of the cast sample. 


\subsection{Measurement of the thermal conductivity}

In the present work, because of its symmetrical characteristics, the radial heat flow furnace was chosen to determine the thermal conductivity of solids ${ }^{11-13}$. The radial heat flow furnace consists of a central heating wire at the axial centre of the sample and a cooling jacket at the outer side as shown in Fig. 3. The central heating wire is at the center of the cylindrical sample and is insulated from the materials with a thin- walled alumina tube. The water cooling jacket is made of stainless steel and is placed on the outside of the sample. To get a radial heat flow, the sample was heated from the center, and the outside of the sample was kept cool by circulating water through the cooling jacket. Details of the experimental procedure, furnace equipments and alloy preperation are described in previous works ${ }^{12,13}$.

Consider a cylindrical sample heated by a heating wire along the axis at the center of the sample. At the steady-state condition, the radial temperature gradient in the cylindrical sample is given by Fourier's law,

$$
\left(\frac{d T}{d r}\right)=-\frac{Q}{A K}
$$

where $\mathrm{Q}$ is the total input power, $\mathrm{A}$ is the surface side area of the sample, perpendicular to the heat flow, and $\mathrm{K}$ is the thermal conductivity of the solid phase. Integration of the Eq. (4) gives,

$$
K=a_{0} \frac{Q}{T_{1}-T_{2}}
$$

where $\mathrm{a}_{\mathrm{o}}=\ln \left(\mathrm{r}_{2} / \mathrm{r}_{1}\right) / 2 \pi \mathrm{L}$ is an experimental constant, $\mathrm{L}$ is the length of the heating wire, $T_{1}$ and $T_{2}$ are the temperatures at the fixed positions, $r_{1}$ and $r_{2}\left(r_{2}>r_{1}\right)$ are the distances from the center of the sample, as shown in Fig. 4. If the values of $\mathrm{Q}, \mathrm{r}_{1}, \mathrm{r}_{2}, \mathrm{~L}, \mathrm{~T}_{1}$ and $\mathrm{T}_{2}$ can be accurately measured for a well-characterized sample, then reliable $\mathrm{K}$ values can be obtained provided that the vertical temperature variation is at a minimum or zero. The sample was heated from the center using a single heating wire (Kanthal A-1) in steps from $100 \mathrm{~K}$ up to $573 \mathrm{~K}$ and then from $50 \mathrm{~K}$ up to $10 \mathrm{~K}$ below the melting temperature of the alloy. The temperature of the sample was controlled to an accuracy of $\pm 0.1 \mathrm{~K}$ with a Eurotherm 2604 type controller.

The sample was kept at steady state condition for at least two hours for a setting temperature. At the steady state condition, the temperatures of the axial position of the sample were measured with a mineral insulated metal sheated 0.5 $\mathrm{mm}$ in diameter K-type thermocouple, and the total input power and the stationary thermocouple temperatures were recorded with a Hewlett Packard 34401 type multimeter and a Pico TC-08 data-logger. Desired power and temperature measurements had been completed for all temperature settings. The schematic block diagram of the experimental set up used to measure the thermal conductivity of the solid phase in the present work is shown in Fig. 5.

The transverse and longitudinal sections of the sample were examined for porosity, crack and casting defects to make sure that these would not introduce any errors to the measurements. The experimental total error in the measurements of thermal conductivity variation with temperature is found to be about $5 \%$ by using the radial heat flow apparatus.

The dependence of the $\mathrm{K}$ of the solid phase on temperature can be expressed as

$$
K=K_{0}\left[l+\alpha_{T C C}\left(T-T_{0}\right)\right]
$$

and the thermal conductivity coefficient, $\alpha_{\mathrm{TCC}}$ is expressed as ${ }^{13}$

$$
\alpha_{T C C}=\frac{K-K_{0}}{K_{0}\left(T-T_{0}\right)}=\frac{1}{K_{0}} \frac{\Delta K}{\Delta T}
$$

where $\mathrm{K}$ is the thermal conductivity at the temperature of $\mathrm{T}, \mathrm{K}_{\mathrm{o}}$ is the thermal conductivity at the $\mathrm{T}_{\mathrm{o}}(373 \mathrm{~K})$ and $\alpha_{\text {TTC }}$ is the thermal conductivity coefficient.

\subsection{Measurement of the electrical resistivity}

The most common way of measuring the resistivity of a material is by using a four-point probe method. This method involves bringing four equally spaced probes in contact with a material of unknown resistance. The probe array is placed in the center of the material. Two of the probes are used to source current, and the other two probes are used to measure voltage. Using four probes eliminates measurement errors due to the probe resistance, the spreading resistance under each probe, and the contact resistance between each metal probe and material ${ }^{18}$. The electrical resistivity, $\rho$, is determined by loading a direct current, I, through the outer pair of probes and measuring the voltage drop, $\mathrm{V}$, between the inner pair of probes which are positioned at a distance of $\mathrm{s}=1 \mathrm{~mm}$. A total of three samples were tested with 5 readings for each sample in order to increase the measurement sensitivity. In this study, the correction factor to be used in calculating the resistivity was determined by referring to the geometric factors in four point resistivity measurement provided by Topsoe ${ }^{19}$. Fundamentally, the electrical resistivity is expressed as

$$
\rho=G \frac{V}{I}
$$

where $\mathrm{G}$ is the geometric resistivity correction factor. There is a functional relation between sample geometry, voltage (V) and current (I) that influences the electrical resistivity. In the calculation of $\mathrm{G}$, which varies with sample and contact geometries, when sample dimensions $t / s \geq 1$ and $\mathrm{d} / \mathrm{s}<40$ (see below) are considered, the following relation can be used ${ }^{19,20}$. 


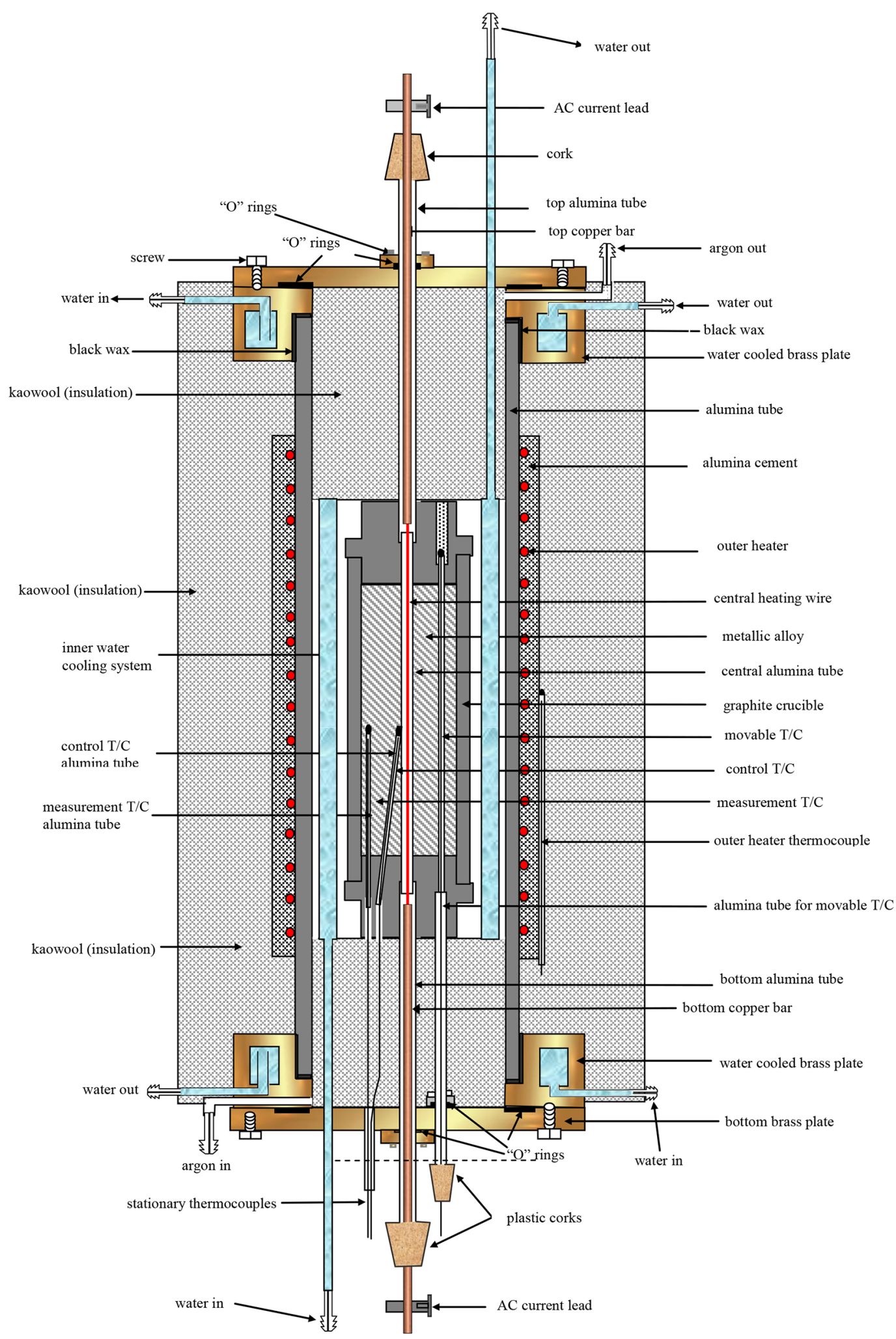

Figure 3. Schematic illustration of the radial heat flow furnace 
where $t$ and $d$ are thickness and diameter of the sample, respectively; $\mathrm{s}$ is the distance between consecutive probes; and $\mathrm{F}_{1}$ and $\mathrm{F}_{2}$ are additional correction factors. Consequently, $\mathrm{G}$ is calculated to be $0.57 \mathrm{~cm}$. The measuring unit was interfaced with a PC for the online data acquisition and processing. A Keithley 2400 sourcemeter was used to provide constant current of $1 \mathrm{~A}$, and the potential drop was detected by a Keithley 2700 multimeter. Platinum wires with a diameter of $0.5 \mathrm{~mm}$ were used as current and potential electrodes. The temperature of the sample in the Nabertherm P320 muffle furnace was controlled with a temperature controller, and the temperature of the sample was measured with a standard
K-type thermocouple. The electrical resistivity strongly depends on temperature. In metals, electrical resistivity increases with increasing temperature. The dependence of electrical resistivity on the temperature is often expressed as

$$
\rho_{s}=\rho_{0}\left[1+\alpha_{E R C}\left(T-T_{0}\right)\right]
$$

and the electrical resistivity coefficient (the slope in the electrical resistivity versus temperature graph) can be given as

$$
\alpha_{E R C}=\frac{\rho_{s}-\rho_{0}}{\rho_{0}\left(T-T_{0}\right)}=\frac{1}{\rho_{0}} \frac{\Delta \rho}{\Delta T}
$$

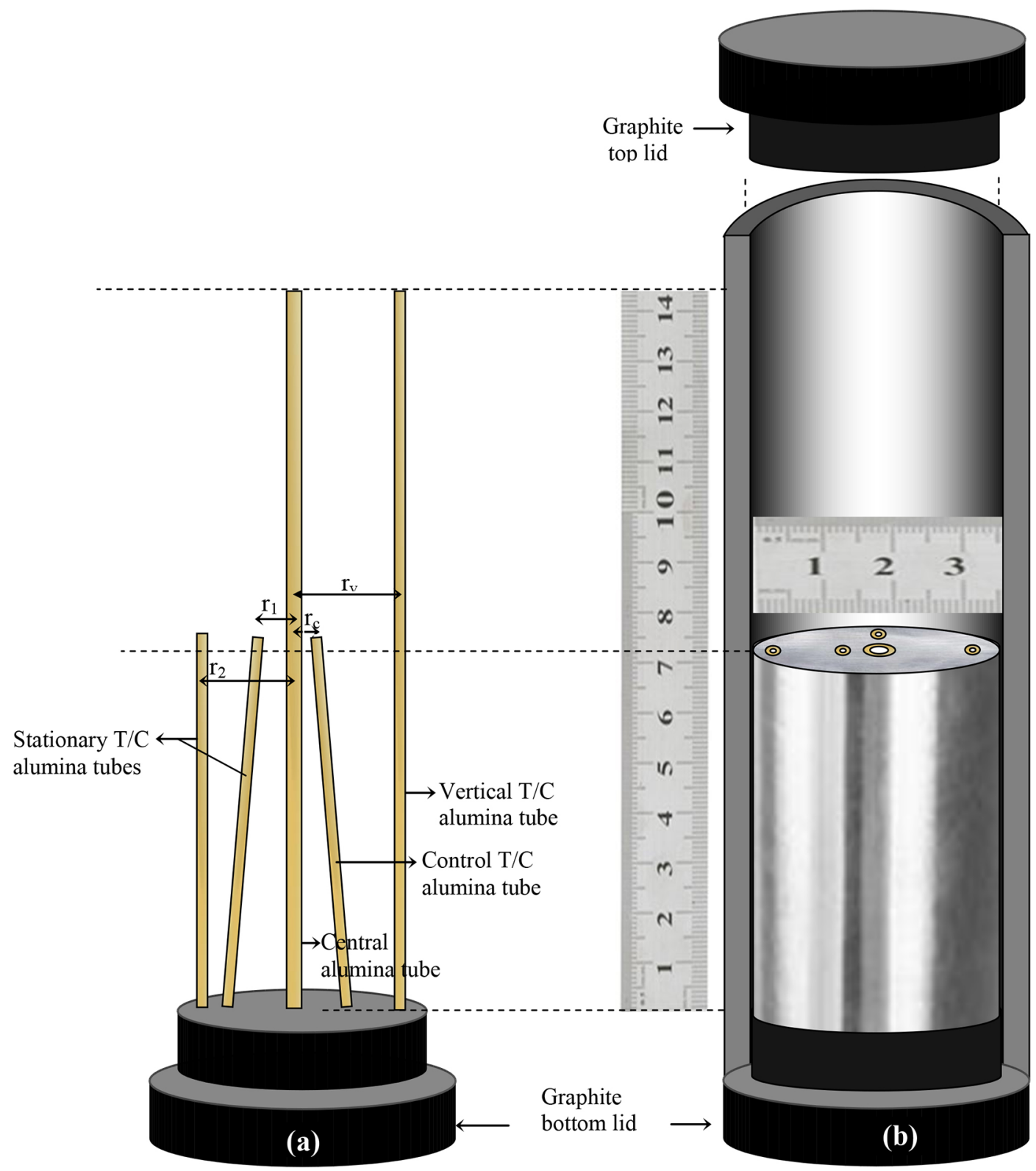

Figure 4. (a) The bottom lid of the sample (b) The appearance of a piece of cylindrical sample in a graphite crucible 


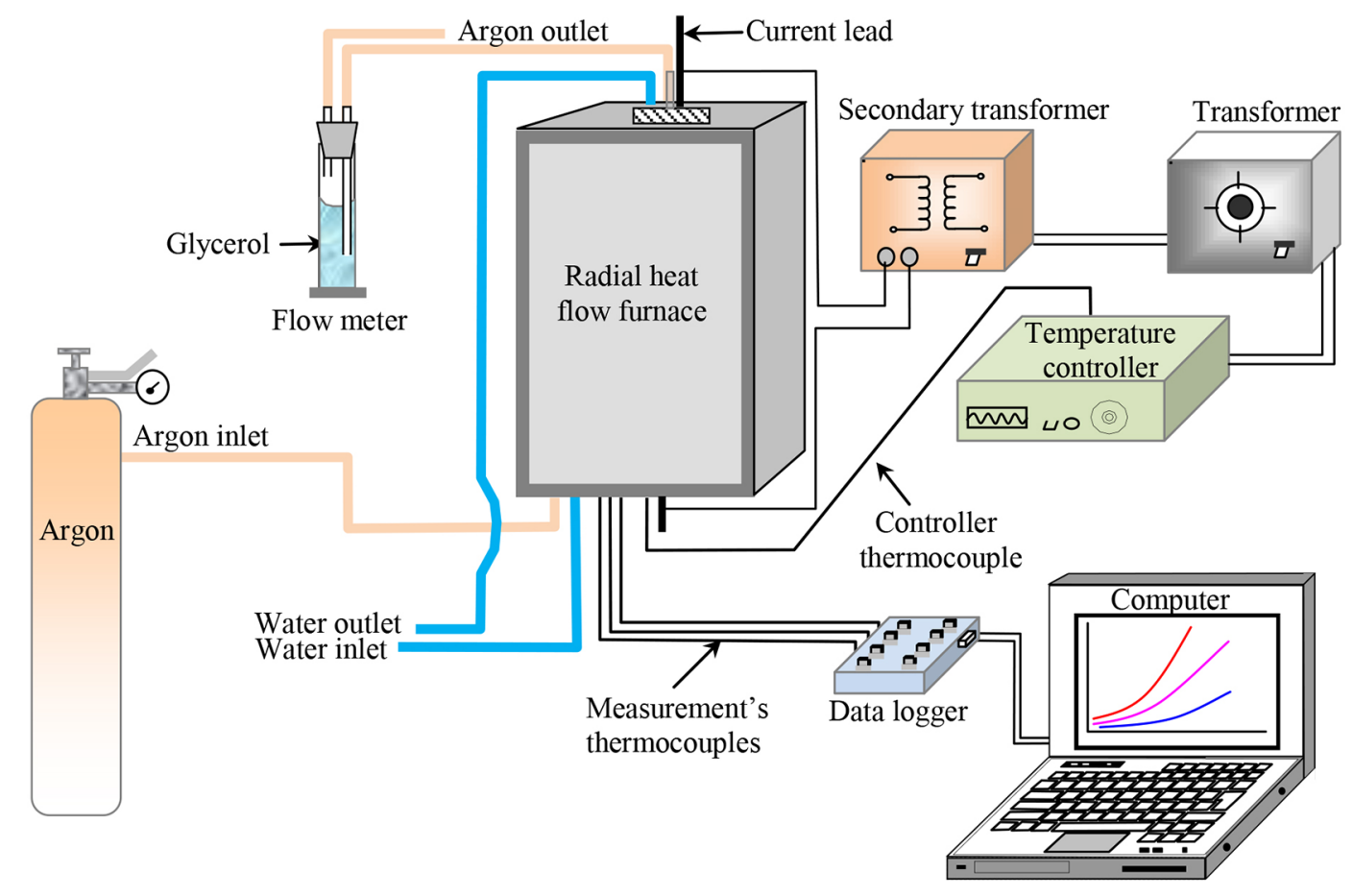

Figure 5. Block diagram of the radial heat flow system

where $\rho_{\mathrm{S}}$ is the electrical resistivity at the temperature $T$, $\rho_{\mathrm{o}}$ is the electrical resistivity at the room temperature, and $\alpha_{E R C}$ is the electrical resistivity coefficient. The error in the electrical resistivity measurements is calculated to be about $5 \%$. The electrical conductivity of the alloy was calculated by taking the inverse of the measured electrical resistivity.

\subsection{Determination of enthalpy, specific heat capacity and thermal diffusivity}

Differential scanning calorimetry (DSC) is carried out together with thermogravimetric (TG) analysis of the sample, using a Netzsch STA 449 C Jupiter balance. The DSC curve shows the amount of heat required to increase the temperature of a sample; and the specific heat capacity, $\mathrm{C}_{\mathrm{p}}$, is determined by

$$
m C_{p} \frac{d T}{d t}=\frac{d Q}{d t}
$$

where $\mathrm{m}$ is mass $(\mathrm{kg})$ of the sample, $\mathrm{dT} / \mathrm{dt}$ is heating rate $(\mathrm{K} / \mathrm{s})$ and $\mathrm{dQ} / \mathrm{dt}$ is heat flow $(\mathrm{W})$. A reference sample with a well-defined specific heat capacity, sapphire in this study, is measured together with the sample. The heat flux and temperature difference between the sample and the reference throughout the heating and/or cooling are measured, and the specific heat capacity of the sample is determined by using Eq. (10).

Measurements of thermal properties were carried out during heating and subsequent cooling regimes at a rate of $5 \mathrm{~K} / \mathrm{min}$ under argon flow $(50 \mathrm{~mL} / \mathrm{min})$. The accuracy of determination of the temperature and enthalpy of reactions were $\pm 0.2 \mathrm{~K}$ and $\pm 5 \%$, respectively.

Another important variable in defining the thermal properties of a material is thermal diffusivity. This is a measurement of the rate at which a material can adapt to a thermal disturbance travelling through it. While thermal conductivity measures the rate at which thermal energy travels through a body, thermal diffusivity deals specifically with the associated rise in temperature measured in $\mathrm{m}^{2} / \mathrm{s}$. After measuring the thermal conductivity using radial heat flow method, the thermal conductivity was substituted into Eq. (11) to calculate the thermal diffusivity:

$$
\alpha=\frac{K}{\rho C_{p}}
$$

where $\alpha$ is the thermal diffusivity $\left(\mathrm{m}^{2} / \mathrm{s}\right), \mathrm{K}$ is the thermal conductivity $(\mathrm{W} / \mathrm{m} \mathrm{K}), \rho$ is the density $\left(\mathrm{kg} / \mathrm{m}^{3}\right)$ and $\mathrm{C}_{\mathrm{p}}$ is the specific heat capacity $(\mathrm{J} / \mathrm{kg} \mathrm{K})$. 


\section{Results and Discussions}

\subsection{Dependency of the thermal conductivity on the temperature}

As can be seen in Fig.6, the value of $\mathrm{K}$ decreases with increasing temperature, and the measured lines of $\mathrm{K}$ variations with temperature for the Al-0.25 $\mathrm{Zr}$ alloy is fairly below the line of $\mathrm{K}$ variation with temperature for $\mathrm{Al}$ ${ }^{21}$. In the case of pure $\mathrm{Al}$ and pure $\mathrm{Zr}$, there were relatively less impurities, such as solute atoms of $\mathrm{Zr}$ in $\alpha-\mathrm{Al}$ matrix, so the scattering of electron by impurity was weak. With the increase of temperature, the vibration of lattice became more severe, which strongly impeded the movement of both electrons and phonons. Thus, the electron-phonon and phonon-phonon scattering became dominant at higher temperature range, leading to a lower thermal conductivity. According to Fig. 6, with increasing the temperature from 373 to $600 \mathrm{~K}$, the values of $\mathrm{K}$ decreased from $240.35,215.76$ and $28.00 \mathrm{~W} / \mathrm{m} \mathrm{K}$ to $233.24,200.05$ and $24.03 \mathrm{~W} / \mathrm{m} \mathrm{K}$, for the pure Al, Al-0.25 Zr alloy and pure $\mathrm{Zr}$, respectively. In addition, the $\alpha_{\text {TCC }}$ values for the pure Al, Al-0.25 Zr alloy and pure $\mathrm{Zr}$ were calculated to be as $1.31 \times 10^{-4}, 3.24 \times 10^{-4}$ and $6.30 \times 10^{-4} \mathrm{~K}^{-1}$ in the range of temperature $373-600 \mathrm{~K}$, respectively, as can be seen in Table 2 .

\subsection{Dependency of the electrical resistivity and conductivity on the temperature}

The temperature dependences of the resistivity of the pure $\mathrm{Al}^{21}$, pure $\mathrm{Zr}^{21}$ and Al-0.25 $\mathrm{Zr}$ alloy are presented in Fig. 7(a). As shown in Fig. 7(a), the resistivities linearly increase with increasing temperature. The line of resistivity

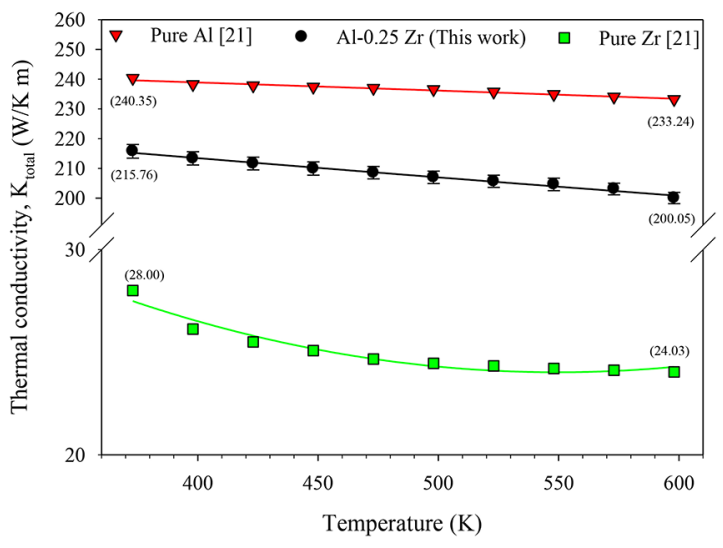

Figure 6. The variations of thermal conductivity with temperature for pure $\mathrm{Al}$, pure $\mathrm{Zr}$ and the $\mathrm{Al}-0.25 \mathrm{Zr}$ alloy

Table 2. Calculated thermal and electrical coefficient of the pure $\mathrm{Al}$, pure $\mathrm{Zr}$ and $\mathrm{Al}-0.25 \mathrm{wt} . \% \mathrm{Zr}$ alloy in the range of $373-600 \mathrm{~K}$

\begin{tabular}{lcc}
\hline Material & $\alpha_{\mathrm{TCC}} \mathrm{x}\left(10^{-4}\right)\left(\mathrm{K}^{-1}\right)$ & $\alpha_{\mathrm{ERC}}\left(\mathrm{x} 10^{-3}\right)\left(\mathrm{K}^{-1}\right)$ \\
\hline Pure Al Pure Zr & 1.316 .303 .24 & 4.263 .833 .16 \\
Al-0.25 wt.\% Zr & & \\
\hline
\end{tabular}

versus temperature for the Al-0.25Zr alloy is slightly higher than the lines of resistivity versus temperature for pure $\mathrm{Al}$, but fairly lower than the line of resistivity versus temperature for pure $\mathrm{Zr}$. The $\rho$ values of the alloy obtained as a function of temperature were found to be in the range of $3.56 \times 10^{-8}$ $7.06 \times 10^{-8} \Omega \mathrm{m}$. The electrical resistivity coefficients $\left(\alpha_{\text {ERC }}\right)$ of the materials calculated from Eq. (9) for the pure Al, pure $\mathrm{Zr}$ and Al-025Zr alloy are given in Table 2. As given in Table 2, the $\alpha_{\text {ERC }}$ values for the same materials were found to be $4.26 \times 10^{-3}, 3.83 \times 10^{-3}$ and $3.16 \times 10^{-3}$, respectively.

Figure 7(b) shows that the values of $\sigma$ for Al-0.25Zr alloy are inversely proportional to temperature and found to be in the range of $1.41 \times 10^{7}-2.80 \times 10^{7} \Omega^{-1} \mathrm{~m}^{-1}$ and the electrical conductivity coefficient was found to be $1.59 \times 10^{-3} \mathrm{~K}^{-1}$ (see Fig.7(b)). It can be observed that increase in temperature values lead to approximately $50 \%$ decrease in the $\sigma$ values.

\subsection{Predictions of thermal and electrical conductivities}

The variations of $\mathrm{K}$ with temperature were also determined from the W-F and S-P equations for the Al-0.25Zr alloy and are shown in Fig. 8 (a-b). In the thermal conductivity process, as can be seen from Eq. 2, the W-F equation contains only electronic contribution ( $\mathrm{K}_{\mathrm{e}}$ ). As can be seen in Fig.8(a), the $\mathrm{K}_{\mathrm{e}}$ values calculated using Eq. (2) decreased from 207.8 to
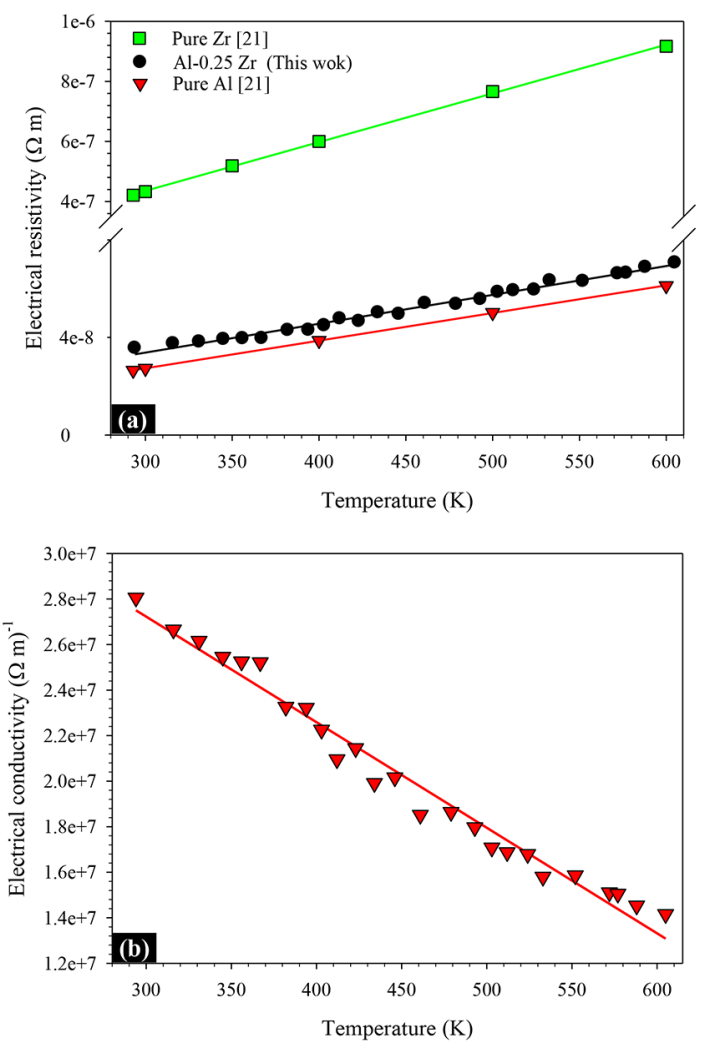

Figure 7. (a) The variations of electrical resistivity with temperature for pure $\mathrm{Al}$, pure $\mathrm{Zr}$ and the Al-0.25 $\mathrm{Zr}$ alloy; (b) the variations of electrical conductivity with temperature for the Al- $0.25 \mathrm{Zr}$ alloy 
198.2 W/Km with increasing temperature. The lattice thermal conductivity $\left(\mathrm{K}_{\mathrm{L}}\right)$ was determined by subtracting $\mathrm{K}_{e}$ values from experimental $\mathrm{K}_{\text {total }}$ values. These $\mathrm{K}_{\mathrm{L}}$ values decrease from 7.53 to $1.79 \mathrm{~W} / \mathrm{Km}$ with increasing temperature. The lattice thermal conductivity $\left(\mathrm{K}_{\mathrm{L}}\right)$ of the $\mathrm{Al}-0.25 \mathrm{Zr}$ alloy contributes $<0.8-3.5 \%$ to the total thermal conductivity $\left(\mathrm{K}_{\text {total }}\right)$ depending on the temperature. The lattice thermal component decreases with increasing temperature (see Fig.8a). Similar trends have been confirmed by various researchers for different metal and alloy systems ${ }^{22-28}$. In the most pure metallic elements, the contribution of the lattice conductivity term becomes low $(\sim 2-20 \%)$ around room temperature, as the conductivity due to electrical charge carriers is dominant ${ }^{29}$. Another important concept in understanding thermal conductivity is that materials are assumed to have a mean free path through which these means of heat transfer can flow. Intuitively, the greater the mean free path is, the better the thermal conduction through a given material will be. The underlying concept behind these methods is scattering of phonons to reduce their mean free paths, thereby reducing the lattice thermal conductivity. For the movement of lattice waves, these obstacles can be other lattice waves, grain boundaries, second phase particles, dislocations, porosity and other imperfections present within the crystal lattice ${ }^{21-23}$. Figure $8(b)$ shows the comparison between the experimental $\mathrm{K}_{\text {total }}$ values and the $\mathrm{K}$ values calculated from the S-P equation (Eq.3). The S-P equation does not neglect the lattice component $\left(\mathrm{K}_{\mathrm{L}}\right)$ that contributes to the total thermal conductivity. As can be seen from Eq. (3), the S-P equation contains constants such as A and B. A term (0.909) is a proposed coefficient due to the Lorenz coefficient difference for different alloys. The S-P equation also assumes that the second term $B(10.5 \mathrm{~W} / \mathrm{Km})$, corresponding to the $\mathrm{K}_{\mathrm{L}}$, is constant and independent of composition ${ }^{15,16}$.

In this study, the value of B for Al-based alloys was used as $10.5 \mathrm{~W} / \mathrm{K}$ m. As can be seen in Fig. 8(b), the experimentally measured $\mathrm{K}_{\text {total }}$ values and the values predicted by the S-P equation are quite good compared to the predicted $K$ values obtained by using the W-F equation. As a result, thermal conductivity, $\mathrm{K}_{\text {total }}$ was highly consistent with the values estimated using the Smith-Palmer law in the current study.

\subsection{The enthalpy, specific heat capacity and thermal diffusivity}

The thermal properties of the Al- $0.25 \mathrm{Zr}$ alloy such as $\Delta \mathrm{H}, \mathrm{T}_{\mathrm{m}}$ and $\mathrm{C}_{\mathrm{p}}$ were investigated using a heating rate of $5 \mathrm{~K} / \mathrm{min}$ in the range $330-1070 \mathrm{~K}$ with DSC analysis in a flow of purified argon. The variation of the heat flow with temperature is given in Fig. 9. A sharp peak occurred during melting. The melting (liquidus) temperature of the $\mathrm{Al}-0.25 \mathrm{Zr}$ alloy was determined to be $945.7 \mathrm{~K}$, and the $\Delta \mathrm{H}$ and the $\mathrm{C}_{\mathrm{P}}$ were calculated as $304.8 \mathrm{~J} / \mathrm{g}$ and $0.907 \mathrm{~J} / \mathrm{gK}$, respectively. Figure 10 shows the temperature dependence of the calculated
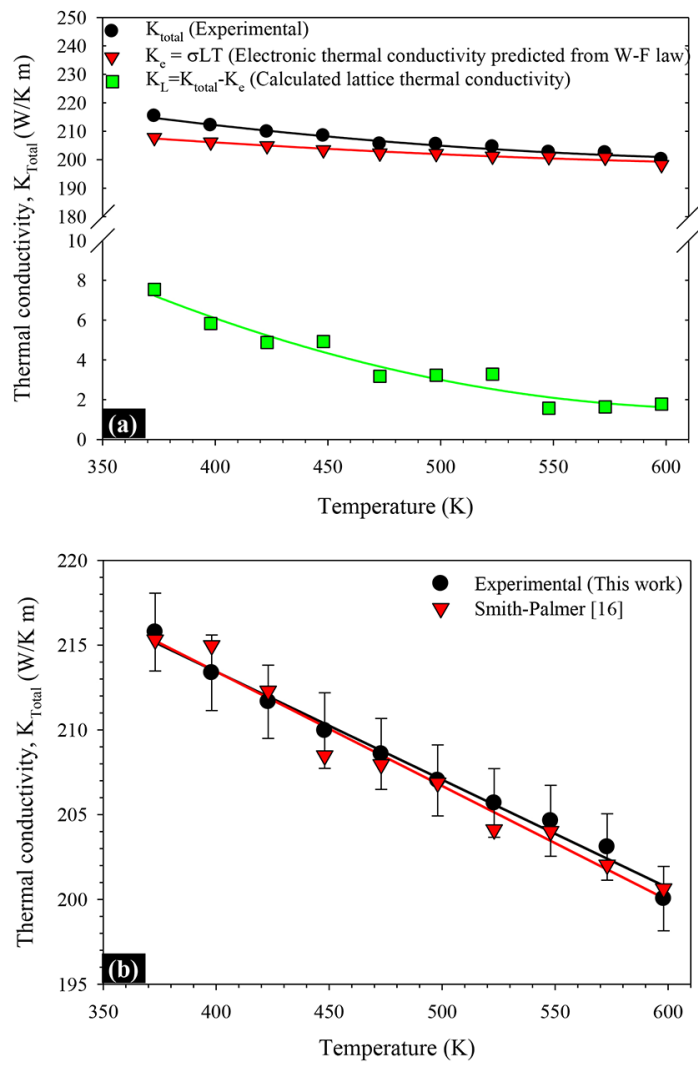

Figure 8. (a) The measured total thermal conductivity $\left(\mathrm{K}_{\text {total }}\right)$, the electronic contribution $\left(\mathrm{K}_{\mathrm{e}}\right)$ and the lattice contribution $\left(\mathrm{K}_{\mathrm{L}}\right)$ of the Al-0.25Zr alloy; (b) Comparison of the experimental $\mathrm{K}_{\text {total }}$ values with $\mathrm{K}$ values obtained from Smith-Palmer prediction for the Al-0.25Zr alloy

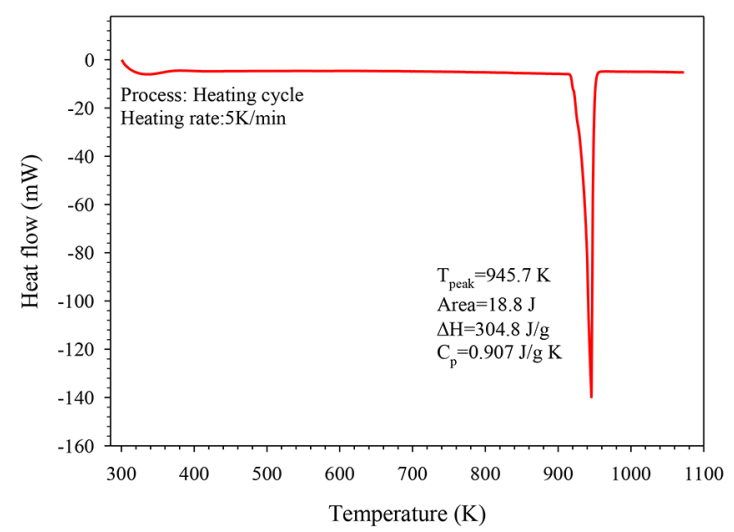

Figure 9. The heat flow-temperature curve of the Al-0.25 $\mathrm{Zr}$ alloy

specific heat capacities for the pure Al, pure $\mathrm{Zr}$ and Al-0.25 $\mathrm{Zr}$. The empirical relationships ${ }^{30-32}$ used in the calculation of the specific heat capacities for solid and liquid phases of pure $\mathrm{Al}$ and pure $\mathrm{Zr}$ are given in Table 3. According to Neumann-Kopp rule, the specific heat capacity of an alloy is equal to the sum of the products of the atomic fraction of the constituent elements and their atomic specific heat 


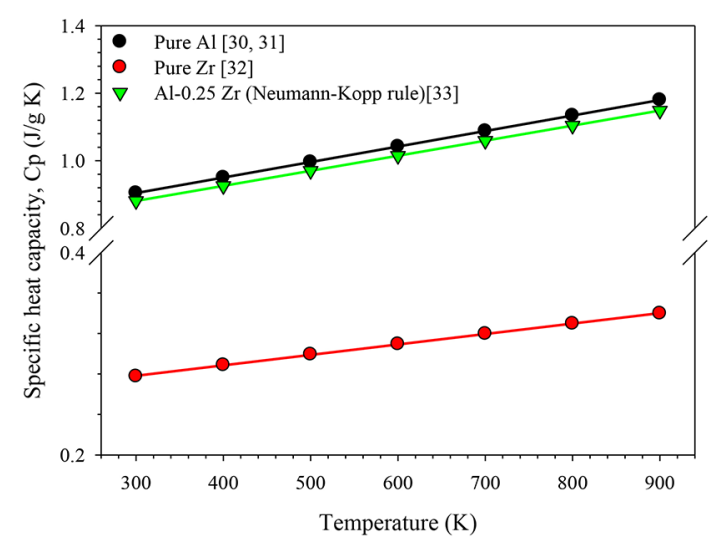

Figure 10. Estimated specific heat capacity for pure Al, pure $\mathrm{Zr}$ and the Al-0.25 Zr alloy

Table 3. Specific heat values of the pure $\mathrm{Al}$ and pure $\mathrm{Zr}$ metals

\begin{tabular}{lcc}
\hline Material & $\mathrm{Cp}$ (liquid)(J/g K) & $\mathrm{Cp}$ (solid)(J/g K) \\
\hline Pure Al & $1.179[31]$ & $0.766+4.59 \times 10^{-4} \mathrm{~T}[31]$ \\
Pure Zr & $0.367[32]$ & $0.250+9.96 \times 10^{-5} \mathrm{~T}-233.7 \mathrm{~T}^{-2}[32]$ \\
\hline
\end{tabular}

capacity. The Cp value calculated from the Neumann-Kopp rule ${ }^{33}$ is slightly larger than the experimentally determined $\mathrm{Cp}$ value (Fig. 9) during solid-liquid state transformation for the studied alloy. As can be seen in Table 3, Cp values for liquid phases of the pure $\mathrm{Al}$ and $\mathrm{Zr}$ metals are generally constant while $\mathrm{Cp}$ in solid phases increases depending on the temperature. The thermal diffusivity data are shown in Fig. 11(a). The corresponding thermal diffusivities were calculated by inserting the thermal conductivities, density and specific heat data for the studied alloy in Eq.(11). The values of thermal diffusivity decrease with increasing temperature. With increasing temperature from 373 to 600 $\mathrm{K}$, the value of thermal diffusivity decreased from $88.3 \times 10^{-6}$ to $82.8 \times 10^{-6} \mathrm{~m}^{2} / \mathrm{s}$ for the $\mathrm{Al}-0.25 \mathrm{Zr}$ alloy. The temperature dependence of thermal diffusivity for the pure $\mathrm{Al}^{34}$, pure $\mathrm{Zr}^{34}$, the studied alloy and some other alloys ${ }^{35-38}$ is shown in Fig. 11(b). The thermal diffusivity of these pure metal and alloys decreased with increasing temperature. The values of thermal diffusivity for the studied alloy are close to the Al-1Si alloy reported by Kim et al. ${ }^{36}$. In the thermal diffusivity, values for both alloys being close to each other, dilution of alloys may play a dominant role.

\section{Conclusions}

The electrical conductivity and some thermal properties of the Al- $0.25 \mathrm{Zr}$ alloy were investigated, and the results are summarized as follows:

1. Dependency of $\mathrm{K}$ in the $\mathrm{Al}-0.25 \mathrm{Zr}$ alloy on the temperature was investigated by using radial heat flow furnace. The thermal conductivity of the Al- 0.25 $\mathrm{Zr}$ alloy linearly decreases from 215 to $200 \mathrm{~W} / \mathrm{m}$
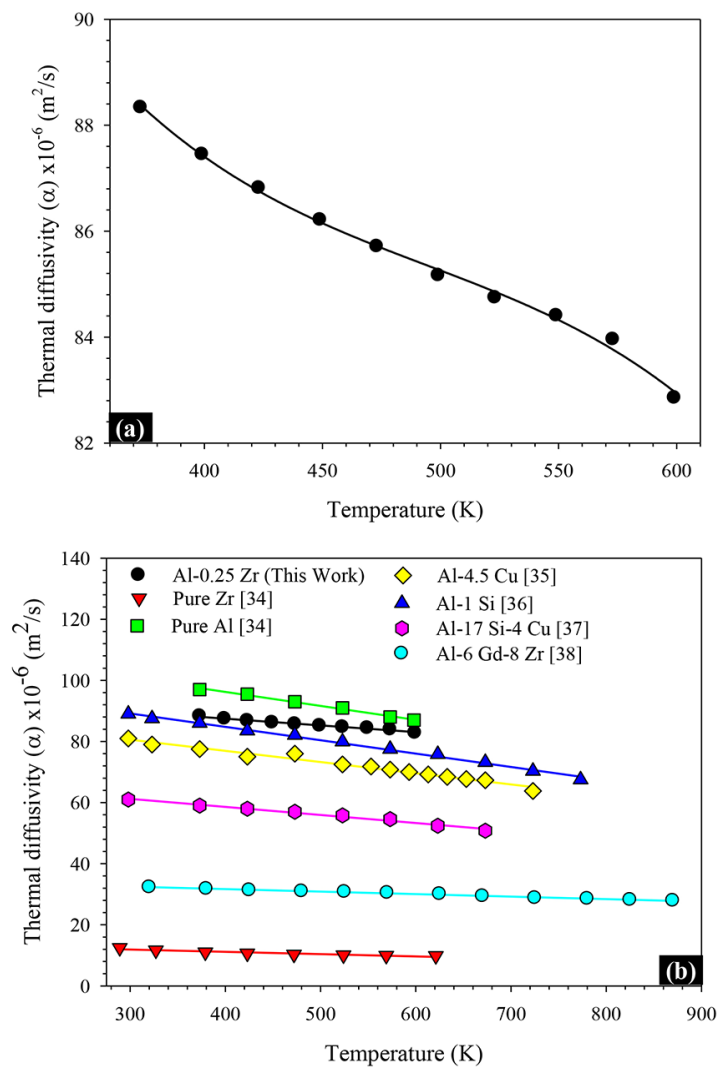

Figure 11. Temperature dependence of the thermal diffusivity of (a) Al-0.25 Zr (b) Pure Al, pure Zr and other alloy systems

$\mathrm{K}$ with increasing temperature. The $\alpha_{\mathrm{TTC}}$ values for the same alloys were determined from the graphs of $\mathrm{K}$ variations with temperature.

2. The measurements of the electrical resistivity were carried out in $300-600 \mathrm{~K}$ temperature range. It indicates that the electrical resistivity of the studied alloy increases from $3.56 \times 10^{-8}$ to $7.06 \times 10^{-8} \Omega \mathrm{m}$ with the increase in temperature. The $\alpha_{\text {ERC }}$ values for the same alloys were also determined from the graphs of $\rho$ variations with temperature.

3. The electrical conductivity, $\sigma$, was calculated by taking inverse of the measured electrical resistivity, and electrical conductivity coefficient $\left(1.59 \times 10^{-3} \mathrm{~K}^{-1}\right)$ was determined from the graph of the $\sigma$ variations at different temperatures.

4. The $\rho$ variations with temperature for the Al- 0.25 $\mathrm{Zr}$ alloy were determined with the W-F and S-P equations by using the measured values of $K$. The relationship between these parameters $(K, \sigma)$ is not very well described by the Wiedemann-Franz law since $\mathrm{K}_{\mathrm{L}}$ includes a significant contribution from phonons. Unlike Wiedemann-Franz law, the SmithPalmer equation contains the phonon contribution, and the values predicted by this equation are in 
good agreement with our experimental thermal conductivity values.

5. The measured melting (liquidus) temperature of the studied alloy was $945.7 \mathrm{~K}$, and the $\Delta \mathrm{H}$ and the $\mathrm{C}_{\mathrm{p}}$ were calculated as $304.8 \mathrm{~J} / \mathrm{g}$ and $0.907 \mathrm{~J} / \mathrm{gK}$, respectively. Thermal diffusivity of the Al- $0.25 \mathrm{Zr}$ alloy decreased with increasing temperature. The thermal diffusivity varied from $88.3 \times 10^{-6} \mathrm{~m}^{2} / \mathrm{s}$ to $82.8 \times 10^{-6} \mathrm{~m}^{2} / \mathrm{s}$ in the temperature range from 373 to $600 \mathrm{~K}$.

\section{Acknowledgement}

This project was supported by Erciyes University Scientific Research Project Unit under Contract No: FOA-2014-5195. The authors thank Erciyes University Scientific Research Project Unit for their financial support.

\section{References}

1. Smallman RE, Ngan AHW. Modern Physical Metallurgy. 8th ed. Oxford: Butterworth-Heinemann; 2014.

2. Hou JP, Wang Q, Zhang ZJ, Tian YZ, Wu XM, Yang HJ, et al. Nano-scale precipitates: The key to high strength and high conductivity in Al alloy wire. Materials \& Design. 2017;132:148-157.

3. ASTM International. ASTM B-94105 - Standard Specification for Heat Resistant Aluminum-Zirconium Alloy Wire for Electrical Purposes. West Conshohocken: ASTM International; 2005.

4. Sakabe S, Mori N, Sato K, Miyake Y, Tanaka A. Development of Extremely-Low-Sag Invar Reinforced ACSR (XTACIR). IEEE Transactions on Power Apparatus and Systems. 1981;PAS-100(4):1505-1511.

5. Sato K, Yamauchi K, Hanaki Y, Kondo T, Yokota M, inventors; Sumitomo Electric Industries Ltd, assignee. High conductive heat-resistant aluminum alloy. United States patent US 4402763. 1983 Sep 6.

6. International Electrotechnical Commission (IEC). IEC 62004 - Thermal-resistant aluminium alloy wire for overhead line conductors. International Standard. Geneva: IEC; 2007.

7. Edris A. High-Temperature, Low-Sag Transmission Conductors. Palo Alto, CA: EPRI; 2002.

8. Zhao Q, Cui X, Qian Z, Liu X. The synergistic effect of Al-B-C master alloy to improve conductivity and strength of 1070 alloy. Journal of Alloys and Compounds. 2015;639:478-482.

9. Cui X, Wu Y, Zhang G, Liu Y, Liu X. Study on the improvement of electrical conductivity and mechanical properties of low alloying electrical aluminum alloys. Composites Part B: Engineering. 2017;110:381-387.

10. Touloukian YS, Powell RW, Ho CY, Klemens PG. Thermal Conductivity: Metallic Elements and Alloys. Volume 1. New York: Plenum; 1970.
11. Ocak Y, Aksöz S, Keslioglu K, Marasli N, Çadirli E, Kaya H. Interfacial energies of solid $\mathrm{CuAl}_{2}$ in the $\mathrm{CuAl}_{2}-\mathrm{Ag}_{2} \mathrm{Al}$ pseudo binary alloy. Thin Solid Films. 2010;518(15):4322-4327.

12. Saatçi B, Ari M, Gündüz M, Meydaneri F, Bozoklu M, Durmus $\mathrm{S}$. Thermal and electrical Conductivities of Cd-Zn alloys. Journal of Physics: Condensed Matter. 2006;18(47):1064310653.

13. Aksöz S, Ocak Y, Marasli N, Çadirli E, Kaya H, Böyük U. Dependency of the thermal and electrical conductivity on the temperature and composition of $\mathrm{Cu}$ in the $\mathrm{Al}$ based $\mathrm{Al}-\mathrm{Cu}$ alloys. Experimental Thermal and Fluid Science. 2010;34(8):15071516.

14. Kittel C. Introduction to Solid State Physics. 6th ed. New York: John Wiley and Sons; 1965. p. 150-153.

15. Poirier DR, Geiger GH. Transport Phenomena in Materials Processing. Pittsburgh: Mineral, Metals and Materials Society; 1994. p. 196-198.

16. Smith CS, Palmer EW. Thermal and electrical conductivities of copper alloys. Transactions of AIME. 1935;117:225-243.

17. Phillips HWL. Equilibrium diagrams of aluminium alloy systems. London: The Aluminum Development Association; 1961.

18. Smiths FM. Measurement of sheet resistivities with the four-poin probe. The Bell System Technical Journal. 1958;37(3):711-718.

19. Haldor Topsøe. Geometric factor in four-point resistivity measurement. Bulletin No. 472-13. Vedbaek: Haldor Topsøe - Semiconductor Division; 1968.

20. Çolak H, Türkoglu O. Structural and electrical studies of Cudoped CdO prepared by solid state reaction. Materials Science in Semiconductor Processing. 2013;16(3):712-717.

21. Touloukian YS, ed. Thermophysical Properties of high Temperature Solid Materials. Volume 1. Elements. New York: McMilllan; 1967.

22. Zheng X, Cahill DG, Krasnochtchekov P, Averback RS, Zhao JC. High-throughput thermal conductivity measurements of nickel solid solutions and the applicability of the WiedemannFranz law. Acta Materialia. 2007;55(15):5177-5185.

23. Schrade M, Berland K, Eliassen SNH, Guzik MN, EchevarriaBonet $\mathrm{C}$, Sorby $\mathrm{MH}$, et al. The role of grain boundary scattering in reducing the thermal conductivity of polycrystalline $\mathrm{XNiSn}$ $(\mathrm{X}=\mathrm{Hf}, \mathrm{Zr}, \mathrm{Ti})$ half-Heusler alloys. Scientific Reports. 2017;7:13760.

24. Li J, Feng Y, Zhang X, Wang G. Theoretical and experimental research of thermal conductivity of silver( $\mathrm{Ag}$ ) nanowires in mesoporous substrate. International Journal of Heat and Mass Transfer. 2018;121:547-554.

25. Zheng Q, Mei AB, Tuteja M, Sangiovanni DG, Hultman L, Petrov I, et al. Phonon and electron contributions to the thermal conductivity of VNx epitaxial layers. Physical Review Materials. 2017;1(6):065002.

26. Guo SD. Anisotropic lattice thermal conductivity in three-fold degeneracy topological semimetal MoP: a first-principles study. Journal of Physics: Condensed Matter. 2017;29(43):435704. 
27. Wang D, Wang G, Li W. Ni substitution enhanced thermoelectric properties of $\mathrm{ZrPd} 1-\mathrm{xNixPb}(\mathrm{x}=0,0.25,0.5,0.75,1)$. Journal of Alloys and Compounds. 2017;692:599-604.

28. Pan H, Pan F, Wang X, Peng J, Gou J, She J, et al. Correlation on the Electrical and Thermal Conductivity for Binary Mg-Al and $\mathrm{Mg}-\mathrm{Zn}$ Alloys. International Journal of Thermophysics. 2013;34(7):1336-1346.

29. Lee S, Esfarjani K, Mendoza J, Dresselhaus MS, Chen G. Lattice thermal conductivity of $\mathrm{Bi}, \mathrm{Sb}$, and $\mathrm{Bi}-\mathrm{Sb}$ alloy from first principles. Physical Review B. 2014;89(8):085206.

30. Guthrie RIL, Iida T. Thermodynamic properties of liquid metals. Materials Science and Engineering: A. 1994;178(1-2):35-41.

31. Brandes EA, ed. Smithells Metals Reference Book. 5th ed. Oxford: Butterworth-Heinemann; 1976. p. 219-221.

32. Pankratz LB, Mrazek RV. Thermodynamic Properties of Elements and Oxides. Washington: US Bureau of Mines 672; 1982.

33. Gopal E. Specific Heats at Low Temperatures. New York: Plenum Press; 1966.
34. Touloukian YS, Powell RW, Ho CY, Nicolaou MC. Thermophysical Properties of Matter. Volume 10. Thermal Diffusivity. New York; IFI/Plenum; 1973.

35. Choi SW, Cho HS, Kumai S. Effect of the precipitation of secondary phases on the thermal diffusivity and thermal conductivity of Al-4.5Cu alloy. Journal of Alloys and Compounds. 2016;688(Pt A):897-902.

36. Kim YM, Choi SW, Hong SK. The behavior of thermal diffusivity change according to the heat treatment in Al-Si binary system. Journal of Alloys and Compounds. 2016;687:54-58.

37. Zhang C, Du Y, Liu S, Liu S, Jie W, Sundman B. Microstructure and Thermal Conductivity of the As-Cast and Annealed Al-Cu$\mathrm{Mg}-\mathrm{Si}$ alloys in the temperature range from 25?C to 400?C. International Journal of Thermophysics. 2015;36(10-11):28692880.

38. Bykov V, Uporov SA, Kulikova TV. Thermal conductivity of Al-Gd-TM glass-forming alloys. Transactions of Nonferrous Metals Society of China. 2015;25(6):1911-1916. 